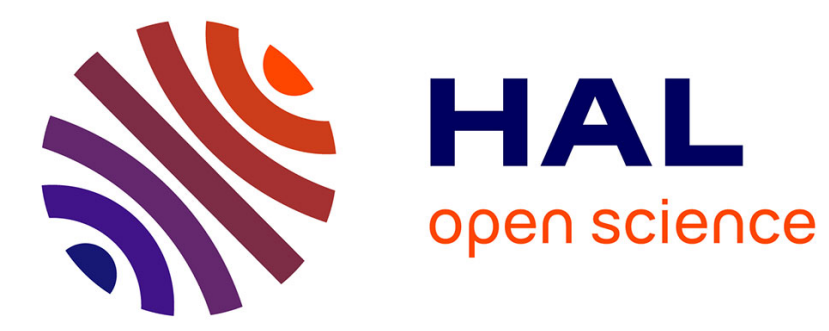

\title{
Performing Cyborgian Identity: Enacting Agential Cuts in Second Life
}

Ulrike Schultze

\section{To cite this version:}

Ulrike Schultze. Performing Cyborgian Identity: Enacting Agential Cuts in Second Life. Working Conference on Information Systems and Organizations (ISO), Dec 2016, Dublin, Ireland. pp.182-197, 10.1007/978-3-319-49733-4_11. hal-01619189

\section{HAL Id: hal-01619189 \\ https://hal.inria.fr/hal-01619189}

Submitted on 19 Oct 2017

HAL is a multi-disciplinary open access archive for the deposit and dissemination of scientific research documents, whether they are published or not. The documents may come from teaching and research institutions in France or abroad, or from public or private research centers.
L'archive ouverte pluridisciplinaire HAL, est destinée au dépôt et à la diffusion de documents scientifiques de niveau recherche, publiés ou non, émanant des établissements d'enseignement et de recherche français ou étrangers, des laboratoires publics ou privés. 


\title{
Performing Cyborgian Identity: Enacting Agential Cuts in Second Life ${ }^{1}$
}

\author{
Ulrike Schultze \\ Southern Methodist University \\ uschultz@smu.edu
}

\begin{abstract}
As people live their lives online more and more, they increasingly rely on digital bodies to extend their senses and to perform identities. With this hybridization of physical and digital embodiments, they become cyborgs and are compelled to negotiate the dualistic space defined by the binary opposition of actual and virtual reality. Whereas actuality typically connotes concrete existence, virtuality signifies phenomena that are ideal, essential and unrealized but that have actual effects.

This paper seeks to understand how individuals negotiate the liminal space that combines virtual and actual reality, especially as it relates to their sense of self, in their performance of cyborgian identities. Drawing on Boland's [1] Engine of Inquiry and Barad's [2] agential cuts as a conceptual infrastructure, this paper analyzes one identity performance of a single Second Life user in order to answer the following research question: How are cyborgian identities enacted in virtual worlds?
\end{abstract}

Keywords: Performative identity $\cdot$ material-discursive practice $\cdot$ virtuality $\cdot$ actuality $\cdot$ cyborg $\cdot$ avatar $\cdot$ Second Life.

\section{$1 \quad$ Research Motivation}

In a society marked by globalization, virtual work and the use of social media, individuals are increasingly experiencing their lives in a liminal space that combines virtual and actual reality [3]. By posting blogs, images, tweets, profiles and films that materialize them in multiple settings, technology users create digital bodies that extend their physically embodied senses and turn them into cyborgs [4], that is, a dialectic synthesis between physical and digital bodies [5]. In light of these multiple embodiments the production of self-identity, that is, "the self as reflexively understood by the person" [6] (p. 52), becomes an increasingly complex project that involves the ongoing negotiation of what identity performances count as "real".

${ }^{1}$ Funding from the National Science Foundation, Grant IIS-0848692, made this research possible. Any opinions, findings, and conclusions or recommendations expressed in this material are those of the authors and do not necessarily reflect the views of the National Science Foundation. 
Despite the recognition that reality and virtuality are inextricably intertwined and mutually constitutive, the virtual is nevertheless frequently separated from the material conditions of daily life [3]. Indeed, the virtual is often conflated with digital environments [7], such that the computer screen becomes the stable boundary between the real and the virtual. However, adopting a definition of virtuality as "that, which is so in essence but not actually so" [8] (p. 2), this paper regards virtuality as a potential reality that stands in opposition to the actual rather than the real.

In order to better understand the dynamics of how identities are produced in the liminality of cyberspace and the dialectic synthesis of people's physical and digital bodies, this study seeks to answer the following research question: How are cyborgian identities enacted in virtual worlds? Adopting a performative lens, identity is defined as an ongoing becoming generated by the repeated enactment of material-discursive practices [2]. Given the hybridity of the identity performances in virtual worlds, this paper focuses particularly on one set of identity practices, namely agential cutting. It is through this practice that virtual and actual aspects of cyborgian identity are cut together/apart.

To answer the research question, this paper draws on empirical material from a study of the avatar-self relationship in the virtual world, Second Life (SL); specifically, the case of Rene, a 33-year-old woman who enacted an avatar named Angela. In addition to Barad's [2] notion of agential cuts, Boland's [1] [9] Engine of Inquiry will be used as the theoretical infrastructure to outline the dialectic space of the virtual and the actual within which Rene's cyborgian identity emerged.

The paper proceeds as follows: prior research on identity performance in virtual settings is briefly reviewed. This is followed by an overview of actual and virtual reality, the Engine of Inquiry and agential cuts, which collectively constitute this paper's interpretive scaffold. The data collection and analysis method is described next. The presentation of the data analysis will be followed by a discussion of the paper's contributions and implications.

\section{Cyborgian Identity Performance}

As the literature on identity performance in computer-mediated settings is vast, illustrative examples of different conceptualizations of cyborgian identity will be presented along the following lines: identity as multiple vs. fixed, and identity as representational vs. performative.

\subsection{Identity as Multiple vs. Fixed}

Turkle's [10] research on multi-user dungeons (MUDs) demonstrated how MUDers used different windows to simultaneously role-play multiple online identities that were unavailable to them in their real lives. The virtual bodies that emerged in these performances were seen as a product of mind, distinct from the user's body [11]. While this conceptualization of cyborgian identity re-produced the Cartesian cut be- 
tween mind and body, it also highlighted the fragmented and distributed nature of self-identity.

However, Turkle's research was criticized for presenting the self as disembodied [11], overly fragmented [12], and insufficiently concerned with sociality [13]. For instance, Shiano [14] reported that most LambdaMOO participants tended to have only one, at most two, avatars and that they strove towards a stable self-presentation to produce long-term social cohesion.

In contrast to depictions of cyborgian identity as multiple and fragmented, other research on virtual worlds has treated the self in more essentialist ways, conceptualizing it in terms of a true, an actual, an ideal and a virtual component [e.g. 15]. For instance, Bessiere et al.'s [16] research on identity exploration in World of Warcraft revealed that the discrepancy between players' virtual and ideal selves was smaller than that between their actual and ideal selves, suggesting that avatars represent not only stable, aspirational identities, but that users have defined identities prior to taking action. This research thus reflects a representational perspective on identity.

\subsection{Representational vs. Performative Identities}

Identity performance can be approached from either a representational or a performative perspective. Representational identity implies that a core essential self not only pre-exists an individual's identity performance, but that it is also the source of such self-presentations [17]. From a representational perspective, virtual bodies are conceptualized as more or less passive signifiers that refer to - and are separated from the user's original (physically embodied) identity. Research concerned with virtual identities' correspondence to the actual self [e.g. 18] is indicative of representational theorizing.

From a performative perspective, in contrast, the self is regarded as the outcome of identity performances, which in turn are the result of unconsciously citing discursively defined practices [19]. Butler [19] argues that, rather than being born female, one becomes a woman by performing such normative practices as putting on make-up and shaving one's legs, which are classified as feminine. In short, an individual is being performed through the enactment of materially and socially constrained practices rather than presenting his/her sense of self. Schultze [20] offers empirical illustrations of performative identity, highlighting that users of a virtual world found themselves becoming who their avatars had performed through mundane everyday practices of the body, such as dressing and gesturing.

\section{Theoretical Framework}

In much of the research on immersive environments, virtuality is defined in materialist terms, drawing the boundary between virtual and actual reality at the interface of the digital environment [7]. Upon donning a head-mounted display in a virtual reality setting or logging in as a 3D avatar, the user is deemed to transition into the realm of the virtual [21], which is frequently regarded as an alternative to the real [8] (p. 46). 
However, these fixed distinctions belie the complex interaction between the virtual and physical reality in everyday life. The increasing entanglement of people and technology calls for a more dynamic conceptualization of the liminal space in which individuals perform identities these days [22]. To this end, a conceptual framework that makes this dynamic and liminal space accessible is developed.

\subsection{Virtual vs. Actual Reality}

Even though the virtual is frequently framed as the opposite of the real, this is a false dichotomy in that "virtual" means "almost" and "as if", implying that the virtual is "that, which is so in essence but not actually so" [8] (p. 2). What qualifies the virtual as reality is that it produces an effect that has physical existence without becoming material itself. For example, an analytical model reflects a virtuality in that its conceptualization of the phenomenon (e.g. the US housing market) represents the phenomenon in essence but not in its "concrete present" form [8] (p. 29). However, such virtual representations are used to make decisions that affect - in real life - the phenomena they model [23].

Such analytical models also reflect an idealized version of an empirical situation; they serve as maps, plans or simulations of phenomena, outcomes and effects as they should materialize [24]. Capturing the "virtue" roots of virtuality's etymology, such models highlight that the virtual represents the "ideally real" [8] (p. 29). Rather than being a mere abstraction, the virtual represents the potentially real [24].

The actual, in contrast, is associated with manifest existence and concreteness [8]. It also connotes objectivity (i.e. existence independent of an individual's attitudes, beliefs and perceptions), authenticity and permanence. As such, the actual is easily conflated with a definition of the reality that refers to the manifest, experienced world [25]. However, in this paper, an experiential view of reality is adopted, which maintains that realness is a matter of degree: objects, actions, thoughts and feelings are experienced as more or less real [25].

While the virtual and the actual are binary opposites, prior research on identity performances in virtual settings highlights a contradiction between them. Users maintain that in virtual settings they are able to enact their true self [26], which remains inaccessible to them in their actual lives. This suggests that the virtual is experienced as more "real" than the actual. The dialectic between the actual and the virtual thus creates tensions that are not only generative but that also render each pole's meaning dynamic.

\subsection{The Engine of Inquiry}

Boland's Engine of Inquiry seeks to explain why conversations [1] and organizational debates [9] - such as those between rational and normative organizational control structures [27] - are never settled but keep revisiting familiar topics in wave-like oscillations. The objective of the framework is to uncover the mechanism through which this dialectic dynamic is produced and sustained. 
The Engine of Inquiry suggests that the structure of language - especially the binary oppositions it creates and its metaphorical nature - produces a perpetual motion machine. Drawing on Lakoff and Johnson's [28] experiential view of language, which argues that metaphors are a way of mapping embodied experiences (e.g. moving up or down) to utterances (e.g. climbing the corporate ladder) to make language meaningful (i.e. up is good, down is bad), the framework constructs an oppositional meaning space. Thus, despite its focus on discursive practices, the Engine of Inquiry fundamentally rests on an embodied - and therefore material - understanding of language.

Lakoff and Johnson [28] note that four schemas underlie the metaphorical structure of everyday language. The four schemas - here illustrated by examples taken from Quinn's [29] research on the ways in which American couples talk about and make sense of marriage - are: ENTITY (marriage as an "indestructible natural object"), CONTAINER (marriage as "being in the same boat"), TRAJECTORY (marriage as an "ongoing journey") and RELATION (marriage as an "unbreakable bond"). Importantly, multiple schemas may be applied to any given phenomenon at the same time.

The Engine of Inquiry suggests that, when multiple metaphor schemas are applied to understanding the binary opposition that informs a phenomenon, tensions arise between them, thus giving rise to the wave-like oscillations that keep boundaries and meanings unsettled. Below, the framework will be described using the virtualityactuality opposition as it relates to gaining self-knowledge through identity performances in virtual worlds (Figure 1).

Fig. 1. Dialectic Process of Performing Cyborgian Identity

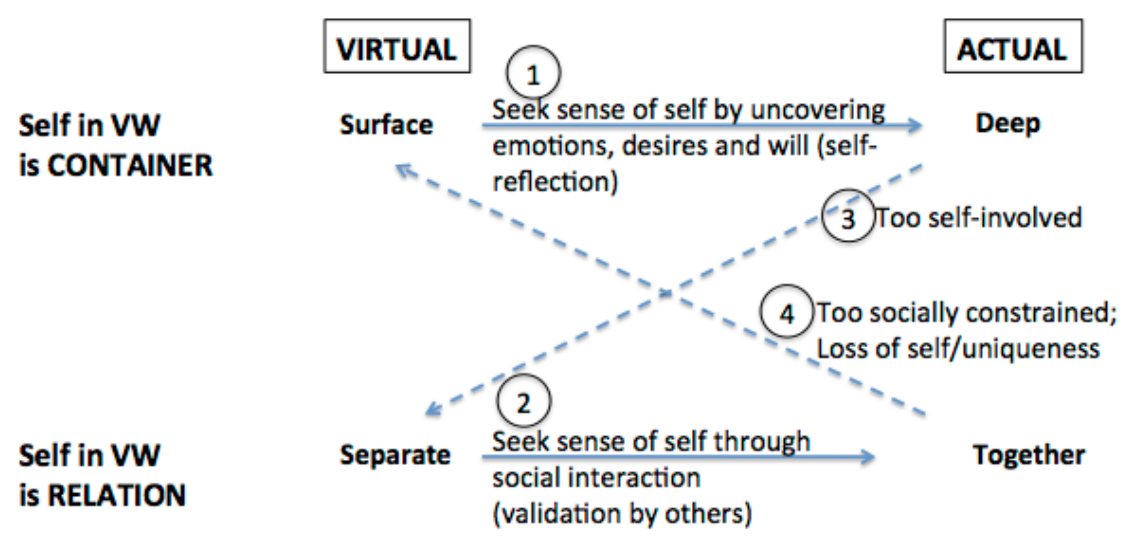

Based on the language used to describe virtual worlds (abbreviated as VW in Fig. 1), the metaphorical schemas of CONTAINER and RELATION seem central to structuring the users' production of what is actual versus virtual. For instance, expressions like "logging in", being "in-world" and having an "immersive" experience, indicate that the simulated world is a container that we can enter or leave (like a building). Virtual worlds are also described as "social networks" in which people form 
"groups", "friend" each other and become "partnered", thus highlighting the relational nature of virtual worlds.

How the distinction between the real and the virtual pole is expressed depends on each schema's entailments in a given context. As a spatial metaphor, the CONTAINER's entailments for performing identity have to do with locating oneself in space. For instance, going deep (i.e. into the center) implies a movement towards the true self associated with actuality (e.g. getting in touch with one's core values; the heart of the matter). In contrast, staying on the surface or periphery signals virtuality in that it implies pretense and superficiality (e.g. putting up a front; faking).

With regard to the RELATION schema, being together with others in meaningful ways is associated with individuals feeling real (e.g. having a sense of belonging). According to Goffman [30], the self depends on interaction to exist socially, implying that social beings need to both present the self to others and to have this performance validated by others in order to materialize as a social being.

In contrast, being separate and isolated (e.g. thinking only of oneself) is indicative of being virtual. Giddens' [31] notion of a "pure relationship" is illustrative of virtuality as defined by the relations metaphor. Entered into for the intrinsic satisfaction they offer and maintained only as long as they deliver enough gratification, participants draw clear personal boundaries rather than become absorbed in and committed to each other in pure relationships. The advancement of the self rather than the development of the couple characterizes this liaison. Being "alone together" [32], i.e. having the assurance of potential connections to virtual others without actualizing relationships, provides another conceptualization of the self as virtual as entailed by the relation metaphor.

Having outlined the structural elements of the framework, we now turn to its motion. Arrow 1 in Figure 1 indicates the natural trajectory of reflexive self-discovery, where idealized avatar-based identity performances that may be 'as-if' (virtual) nevertheless generate insights into the user's true emotions, deep desires and core values (actual). Similarly, arrow 2 signifies a natural search for meaningful social connections as one's sense of self depends on it. This suggests a progression from an identity performance that is self-absorbed (virtual), to one that recognizes its interdependence with others (actual).

What turns this framework into a perpetual motion machine, however, are arrows 3 and 4, which represent a switch in the schema used to organize one's experiences. Importantly, switching metaphorical schema instantiates a reversal of meaning. For instance, while being in touch with one's deep-seated emotions and core values is indicative of being true to one's actual self within the CONTAINER schema, from a relational perspective such behavior may be self-indulgent and inconsiderate of others' needs. Thus, what is deemed actual in the CONTAINER schema, is virtual on the RELATION register.

Similarly, while the actual pole in the RELATION schema is characterized by being dependent on and socio-emotionally entangled with others, it also implies a loss of self as individuals subjugate some of their uniqueness for the sake of social harmony. The high degree of social agreement that signifies the actual in the RELATION schema thus simultaneously implies virtualness in the CONTAINER schema. The 
reversal of meaning associated with a switch in metaphorical schema ensures that individuals' questions about who they are and who they might be as cyborgs is never settled. As such, the Engine of Inquiry represents a performative view of language in which utterances do not only represent phenomena, but also produce them [33].

Since Boland [1] [9] argues that schema switches occur when a metaphor has been saturated or pushed too far, the Engine of Inquiry offers us a theoretical framework for understanding when and why users of virtual worlds segment their fluid and ongoing experience as a cyborg into more or less "real" aspects as they make sense of their identity performances and of their emergent self-identity. Barad's [2] concept of agential cuts as material-discursive practices provides a conceptual infrastructure for theorizing this process of identity enactment.

\subsection{Agential Cuts}

Barad's [2] agential realism advances a fully relational ontology in which entities only exist in relation to others. Phenomena (e.g. selves, technologies) have no existence independent of each other; rather they are brought into being in practice. Instead of a world made up of discrete entities that are brought together through interaction, Barad [2] conceptualizes a world made up of fluid entanglements that are separated through agential cuts.

Nyberg [5] offers the following example of agential cutting: call center customers experience the components that constitute service delivery (i.e. the telephone system, the computer systems, the customer service representative, etc.) as an entangled whole until customer service representatives distance themselves from the (failing) technology with such utterances as "the computer has a mind of its own". Enacting such cuts between technological and human actors, the elements in a sociomaterial assemblage are given identity, properties and agency.

However, Barad highlights that agential "cuts are enacted not by willful individuals but by the larger material arrangements of which 'we' are a 'part" [2] (p. 178). In other words, agential cutting is not merely a discursive act performed by an agential individual, but the performance of everyday material-discursive practices that draw on the sociomaterial infrastructure in which an individual is entangled. Furthermore, "cuts cut 'things' together and apart. Cuts are not enacted from the outside, nor are they ever enacted once and for all" [1] (p. 179).

Combining Boland's Engine of Inquiry with Barad's agential cuts, we note that schema switches are indicative of agential cuts as the diagonal arrows indicate a severing of the cyborgian entanglement between the user's self-identity and his/her identity performance in avatar form. Our empirical data analysis demonstrates how this conceptual framework provides us with insight into how cyborgian identity is enacted in virtual worlds. 


\section{$4 \quad$ Method}

To explore cyborgian identities in their constant state of becoming through the ongoing negotiation of what counts as real in the intertwining of actual and virtual reality, this paper relies on a single case of a female resident of Second Life, who was interviewed as part of larger study of US-based SL users that spent at least 10 hours a week in-world. Given the need for a micro-level analysis of the material-discursive practices of agential cutting that this paper seeks to explore, a single case offers the requisite empirical richness.

The case was chosen for its potential for generating insights into the dynamic nature of cyborgian identity performance. The participant, Rene, ${ }^{2}$ had considerable experience in virtual worlds, having spent 10 months in SL and a number of years in MUDs. She was also very introspective and articulate. Moreover, she used her avatar, Angela, for highly personal and profound identity work. As such, Rene might be classified as an extreme case [34], in that her use of SL demonstrated cyborgian identity performance naturally and intensively, thus enabling comprehensive theorizing.

Rene was 33 years old, single and a minority: part African American, part Native American. She had attended a highly competitive magnet high school for the talented and gifted, and subsequently earned an undergraduate degree in Management Information Systems, as well as a Masters in Business Administration. At the time of the interview, she was working in a small insurance office, where she dealt with accounts payables, receivables, newsletters, and client relations.

Rene had initially entered SL to learn more about Gorean role-play, which enacted unconventional intimate relationships. Instead of joining an established role-play community though, she developed her own character and role-play scenarios with close friends. Angela played both dominant and submissive roles. As a dominant, Angela had three male submissives; as a submissive, she had a master (Ira), with whom she was also "partnered" (i.e. married) in SL. Together, these four men made up her "SL family".

Data were collected in two phases during Fall 2008:

- A 2-hour, face-to-face interview: After meeting briefly in a coffee shop, this interview was conducted in the author's office, which offered privacy and Internet access so that Rene could log onto SL and provide the researcher with an overview of her life there. A key objective of this in-person meeting was to build the rapport and trust needed for the longitudinal data collection that followed.

- Three 1-hour phone interviews about Rene's weekly photo-diary: Diary methods approximate observational research, but rely on research participants to serve as adjunct ethnographers, capturing naturally occurring events, as well as their meaning and significance. Following Latham [35], Rene was asked to proceed with their SL activities as normal, but to take a snapshot of events that were in some way meaningful, significant or important to her. Each snapshot was then annotated by answering when, what, why, who and how questions. Each photodiary included

2 All names are pseudonyms. 
five snapshots and was submitted to the author ahead of the scheduled phone interview.

Given the considerable time commitment required, Rene was paid $\$ 150$. With her permission, all interviews were tape-recoded. 
Data analysis proceeded as follows:

1. extracting excerpts from interviews and photodiaries related to identity performances and the production of self-identity;

2. evolving the metaphorical schema outlined in Figure 1; even though the Engine of Inquiry was presented in the theory section, Figure 1 represents an empirically grounded adaptation of the framework;

3. developing situated meanings of virtual and actual reality; the meanings Rene associated with the positions that made up the dialectic space (surface, deep, separate, together) were identified (i.e. Table 1); and

4. tracing the dialectic movements of specific identities; to demonstrate the pendulum-like motion of performing cyborgian identity, various identity performances were traced through the framework. Agential cuts were also identified. One of these identity performances, i.e. Ira's partner, will be presented below.

\section{Empirical Analysis}

\subsection{Dialectic Space: Virtual vs Actual}

Table 1 summarizes the dialectic space through which Rene defined the various meanings of virtual and actual reality. Importantly, the empirical examples used to develop this meaning space demonstrate the intertwined nature of meaning/discourse and matter/technology.

Table 1. The Dialectic Space of Cyborgian Identity Performance

\begin{tabular}{|c|c|c|}
\hline & VIRTUAL & ACTUAL \\
\hline $\begin{array}{l}\text { Self in virtual } \\
\text { world is } \\
\text { CONTAINER }\end{array}$ & $\begin{array}{l}\text { Surface } \\
\text { - escape; endless possibilities } \\
\text { through playfulness and cre- } \\
\text { ativity } \\
\text { - avatar as character distinct } \\
\text { from user's self-identity }\end{array}$ & $\begin{array}{l}\text { Deep } \\
\text { - quest to recover true self and } \\
\text { uncover hidden facets of self } \\
\text { - avatar as extension of user's } \\
\text { self-identity }\end{array}$ \\
\hline $\begin{array}{l}\text { Self in virtual } \\
\text { world is } \\
\text { RELATION }\end{array}$ & $\begin{array}{l}\text { Separate } \\
\text { - game: inconsiderate of oth- } \\
\text { ers' feelings; no morals, ly- } \\
\text { ing, misrepresentation } \\
\text { - self-centered: acting in own } \\
\text { self-interest }\end{array}$ & $\begin{array}{l}\text { Together } \\
\text { - simulation of real life: moral } \\
\text { obligation to person behind } \\
\text { avatar } \\
\text { - family: commitment to others }\end{array}$ \\
\hline
\end{tabular}




\section{Surface}

Rene's principal use of SL was as a diversion and an "escape" from her "real life" (RL), which she described as "out of control" and "unfulfilling". Discursive practices of distinguishing "Second Life" for "first" or "real life" enacted the virtual as a distinct space separate from actual reality:

When I go in Second Life most of the time, it helps me just not think about [my RL worries]. It helps me regain some control over my happiness and I just don't even think about [RL].

Engaging primarily in role-playing and building, both of which represented playful, creative expression rather than a quest for self-knowledge for Rene, she enacted the virtual as a place of endless possibility:

And I think that's what I like the most about role-playing online because you don't have any boundaries. It can be whatever you want it to be.

Creating an avatar with a different name and an appearance that did not mirror Rene's physical embodiment - Angela had a light complexion and waist-long, yellow-blond hair and wore "edgy" outfits that Rene would never wear - produced Angela as a character that was not only distinct from Rene's self-identity, but also independent of her player:

Suddenly she [Angela] is her own person. I mean, she's me, but she's has her own persona; she has her own style.

\section{Deep}

Paradoxically, the separation between the virtual and the actual that such materialdiscursive practices as anonymity, role-playing and world-building produced, also created the conditions for identity work. Self-reflection and experimentation with alternate ways of being made it possible to gain deep self-knowledge, implying a profound entanglement between users' avatar-embodied identity performances and their sense of self. Observing her identity-performance as Angela, Rene noted that she became a different person in SL even though "mentally" her avatar was indistinguishable from her:

She's me! [Laughter] I don't know. I mean, mentally she's me ... She's a lot tougher than I am. [Laughter] That's for sure. ... Oh, because I'm a wimp. ... when I role-play her, she pretty much stands her ground. Whereas me in real life, I don't always have that in me, you know. I can be somewhat of the push-over.

Rather than making distinctions between herself and her avatar, Rene created continuity with Angela:

Angela is an extension of me. So if somebody offends her, they're offending me because she is my personality. She is my creativity. ... I'm playing me, you know. I'm my personality. I'm playing her as if; if I had these capabilities this is what I'd do. And somebody insults or disrespects that, it's a lot more personal. 
Rene thus acknowledged that SL not only had an effect on RL, but that events in virtuality were likely to be more consequential to the self (i.e. injuries are "a lot more personal") than actual events. Given that online identity performances were seen as an expression of the user's creativity, and supposedly less encumbered by actual constraints such as the user's physical embodiment, for example, insults in SL struck Rene in her core.

\section{Separate}

Misrepresentation, lies and morally questionable behavior were ways in which SL relationships (re)produced virtuality. For example, Rene had role-played with Carl who claimed to be unmarried in RL. After she had allowed herself to fall in love with him, she learned that he was actually married. She concluded that "[SL]'s a fantasy world, and you do come to realize that a lot of people don't take it so seriously". Subsequently, she classified all interactions with Carl as "strictly SL", thereby changing her "perspective on the time that we spent together and what it means when we are together".

Even though she had struggled to deal with Carl's deceit, she vigorously defended her right to present herself in non-representational ways:

There's this guy I was becoming friends with. ... He asked for a photo of me [in RL]. And the moment he saw it, he said, "Hmm, different". And then he took me off his Friends List and put me on mute [i.e. blocking all her messages to him]. Because I didn't look like Angela. Nobody in SL looks like their avatar! It's always an exaggerated perversion of who they are. And who's to say that I have to be some half Native American, half black chic. ... It doesn't make sense. It is a fantasy world after all.

\section{Together}

Even though Rene engaged in role-play most of the time, she maintained that she performed an identity that was in line with her self-identity:

And there's some people that are so extreme into their fantasy world that you'll never see who they really are and what they're really like. Whereas, I try to be as true to myself as possible.

She resented when people treated SL like a "game", with which she associated a lack of consideration for the feelings of the actual person behind the avatar:

I don't approach it [SL] as a game like some people do and that's probably my biggest pet peeve because it's a simulation of life. It's not an actual game. ... You're dealing with real people, real feelings. So even though the environment is fake and the avatar is fake, the person behind it - the personality, the emotions - everything is real.

The home that Rene built for her SL "family" (i.e. her "master" and three submissives) made these relationships "real", "solid" and permanent, implying that they persisted outside of SL also: 
You know the family was already established, it's just now [with my SL home completed] it feels real and solid and you know, unbreakable. ... It's not like I'm just floundering. I have a real home, I have, you know, definite family ... it's not going away.

\subsection{Perpetual Motion: Performing Cyborgian Identity}

Having outlined the meanings Rene gave to the four positions in the dialectic space marked by the virtual-actual opposition, her movement through this space will now be traced using one of her identity performances. Figure 2 summarizes her ongoing becoming as a partner to her "master" and "husband", Ira.

Fig. 2. Performing Ira's Partner

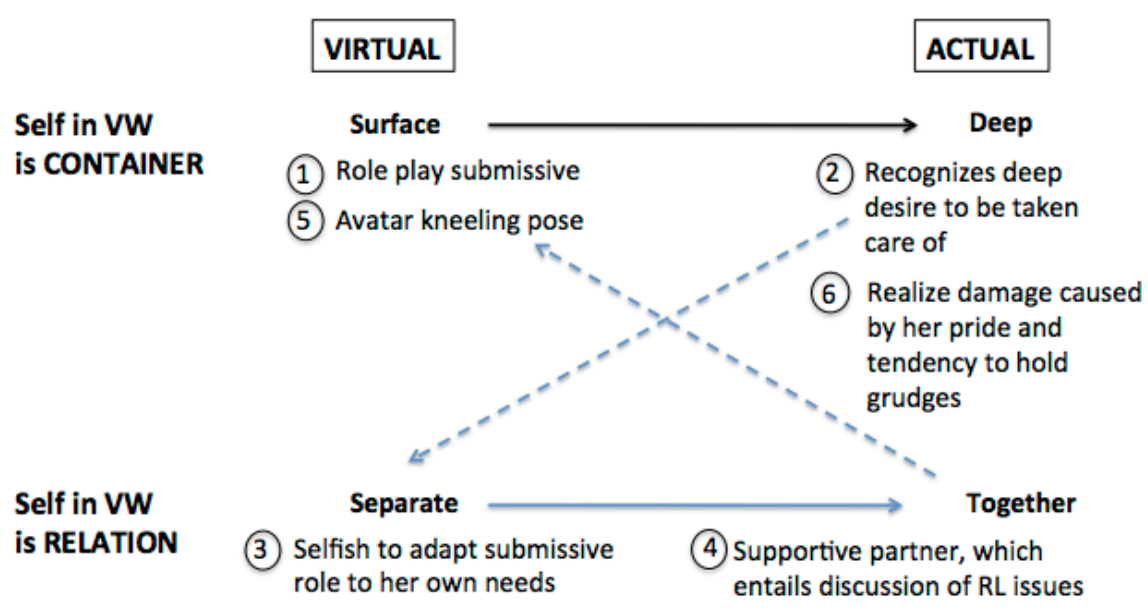

When Rene first met Ira, she was reluctant to role-play with him because he was looking for a submissive and she considered herself too dominant to pull off that role:

[As a submissive] you're giving up yourself; you're opening yourself completely to another person. You're at your most vulnerable because they can make decisions for you and they can basically ... determine how you should feel and what you should think, etc.

Nevertheless, she decided to role-play the submissive (1: surface):

Angela's role from the moment that she met Ira was always a submissive. ... if I'm being a submissive with Ira in SL that's more Angela than Rene.

"Being a submissive with Ira" was enacted through such material-discursive practices as wearing "his collar" and "silks" (i.e. bikini top with skirt slit up both sides), performing acquiescent poses (e.g. kneeling) and addressing Ira as "Master". Even though playing this role was "more Angela than Rene", it made an inaccessible, "hidden side" of Rene available to her, highlighting a deeply held desire to be taken care of (2: deep): 
She [the submissive Angela] is a hidden side of me that I don't think I could ever express in real life. ... I love the feeling of being safe and protected and cherished, like you're their number one jewel in the whole world.

Indicative of the lack of separability between her sense of self and her role as Ira's submissive partner, Rene found it difficult to maintain a subservient attitude. She noted that she rarely performed submissiveness when she was with Ira, which raised questions about the status of their relationship (3: separate):

We've had conversations before where he wasn't sure if it was what I still wanted to be partnered. And it's important for me to kinda reassure him that it is what I want. Because I don't want him to feel uncomfortable or for him to feel like he's not as important to me in my life anymore. So when we're on SL, we try to role-play ... sometimes when we are talking about real life things, I have to remember who I am in my SL avatar and how I should really relate to him and how I should behave around him.

This interview quote illustrates Rene's realization that her identity performance entangled too much of her actual, dominant self at the expense of Ira's needs. It thus highlights not only a switch in metaphorical schemas (from self as CONTAINER to self as RELATION), but also an agential cut as Rene recognizes that she needed to be "who I am in my SL avatar" whenever she is interacting with Ira in SL. She enacted this cut by performing such material-discursive practices as wearing silks and calling him "Master". These practices helped her "relate to [Ira]" and "behave around him" in the way that she "should".

Rene's desire to perform her role as a submission more credibly in order to fulfill Ira's emotional needs, paradoxically also produced a "real relationship" that involved the people behind the avatar (4: together). This meant that Ira and Rene talked about RL issues more and more while in-world. Rene, however, became increasingly frustrated as conversations about their actual lives dominated their interactions in SL:

And that's not bad [to talk about RL] like once a week, but when every time I talk to him it's the same thing, it starts to get a little annoying to me. And it starts to depress me. It really stresses me out, because then I start worrying about what's going on with him [in RL]. ... And it's just like, "can we just forget about it all for a bit while we're on SL and just try to be happy and not think about the problems for just a little bit?" Because that's kind of the whole point of SL.

The interview quote suggests that her identity performance as Ira's partner had become too "real" in that it was no longer submissive-dominant role-play; instead Rene was "worrying about what's going on with him [in RL]"). The "stress" this caused Rene suggested that their SL liaison had gone too far and had lost its playfulness and promise of escape.

One particular incident highlighted the challenge associated with their relationship becoming too real (i.e. "crossing the line"); Rene had become "really mad" at Ira for failing to take her side on an issue: 
I should not have gotten that upset with him. And that's probably one of the problems with having real life relationships and SL relationships, because sometimes you forget your role, your place on SL and [by getting mad with Ira] I definitely crossed the line there.

To restore her identity as Ira's submissive partner, Rene relied on her avatar's animations, especially the kneeling pose, to enact an agential cut that separated her sense of self from her identity performance as Ira's partner (5: surface):

Probably the conversation initially was more Rene with Ira's player and then [once in a kneeling pose], it's more, “okay, I'm going to be Angela, I'm going to be subservient and my master is right or it doesn't' matter who's right, I just need to respect him and get his forgiveness etc." It was like me switching from Rene to full Angela at one point.

By placing her avatar in a kneeling pose and thereby "switching from Rene to full Angela", Rene also switched from the RELATION schema to the CONTAINER schema, moving from a focus of self in relation to Ira, to one of self in relation to her avatar. The kneeling pose was also performative in that it enacted an ideal submissive. This not only enabled Rene to "respect her master" in her identity performance on SL, but it also affected her actual emotions (6: deep):

In this moment [where she is kneeling], it calmed me down in real life too. Because I was pretty huffy. [Laughs] ... I can be very stubborn and prideful and whenever I kneel [as Angela], it's kind of like it's giving me permission to let go and just do the right thing even if it affects my pride.

Furthermore, the incident made Rene reflect on how destructive her pride and her tendency to hold grudges was both in SL and in RL:

Probably [in RL I learned] the same thing. Don't hold grudges and don't focus and complain on a matter to the point where you've crossed the line ... up to a certain point it's justified but once you get past that certain point, it's just painful for everybody.

Even though the movement through the dialectic space continued in Rene's ongoing cyborgian identity performance, the length restrictions of this article prevent any further illustrations here.

\section{Discussion and Conclusion}

The objective of this paper is to gain insight into the ongoing becoming as a cyborg. Key assumptions underlying this research include that: (i) identity is performative, implying that it is the result of enacting everyday material-discursive practices, (ii) cyborgian identity performances occur within a dialectic space defined by opposing poles of virtual and actual reality, (iii) based on the oppositional and metaphorical structure of language, the dialectical interplay between virtuality and actuality functions like a perpetual motion machine (i.e. Engine of Inquiry), such that neither cy- 
borgian identity nor the meanings of the actual and the virtual will ever be settled, and (iv) agential cutting that cuts together/apart online identity performances and selfidentities represents a key practice by which individuals keep a given cyborgian identity performance going.

Into the research question "How are cyborgian identities enacted in virtual worlds?" the paper's empirical analysis provides the following insights:

- The material conditions of the technology (e.g. making oneself present in a virtual body distinct from one's physical embodiment) compel users to confront questions of how the multiple, situated identities they perform as an avatar relate to their more permanent sense of self. At times, they experience their performances online as inseparable from who they are; at other times, their avatars seem to be independent entities. Rene's discursive practices, which continuously switched between "I" and "she" to describe her actions as Angela in SL, suggest that the configuration of cyborgian identity as an entanglement of avatar and physically embodied user is fluid and remains unsettled.

- In making sense of these different experiences with being a cyborg, users distinguish between their personal relationship with their avatar and their relationship with others as avatars. These two dimensions of cyborgian identity are reflected in the framing of the self as container and as a set of social relations respectively. In Rene's case, questions about her avatar-self relationship revolved around the extent to which her creativity, thoughts and feelings were entangled with Angela, and the kind of identity they produced (e.g. someone tougher than the wimp she was in $\mathrm{RL}$ ). In contrast, her self-other relationship as a cyborg was more concerned with questions of authenticity and moral obligations, i.e. the extent to which she participated in validating others - and therefore her own - actual existence despite the fakeness of the setting.

- Even though there are many agential cuts that are enacted continuously and in ways that individuals do not consciously perceive - e.g. apparatuses like the technological configuration of SL and the material-discursive practices of separating this virtual from the actual by enacting fantasy role-play scenarios - there are nevertheless situations in which cutting is agentially performed by individuals [see also 5]. For example, when she got a sense that her performance as Angela was no longer sufficiently distinct from her dominant self (i.e. when it had become too real), Rene relied on her avatar's embodied practices (e.g. wearing a collar, kneeling) to restore Angela's identity as Ira's submissive partner. This practice of agential cutting produced Angela as a somewhat independent being with her own identity and agency. Angela's embodied actions (e.g. wearing silks, referring to Ira as "Master" in text chat) were performative in that they affected Rene's physically embodied emotions and reminded her to limit the degree to which she allowed herself to be entangled with Angela.

This research makes two key of contributions:

- Given recent calls to develop more performative and processual theories of identity work in the liminality of cyberspace [e.g. 22], this paper outlines a theoretical scaf- 
fold for how people (re)produce the dialectical space that constitutes the virtual and the actual. Boland's Engine of Inquiry [1], a framework that was developed to theorize the performativity of language, is expanded to help explain the performativity of the material-discursive practices of cyborgian identity performance. Even though this paper has demonstrated the Engine of Inquiry on a rather limited - albeit rich - empirical data set, the framework appears to hold much promise with regard to theorizing how people produce their identities in the face of the increasing entanglement of physical and digital embodiments.

- The notion of agential cuts has become part of the agenda of sociomaterial theorizing in IS research. This paper provides not only an empirical illustration of how agential cuts are enacted unconsciously through everyday material-discursive acts in virtual worlds, but it also highlights the potentially agential nature of cutting practices. As such, this paper provides empirical insight into when and - to some extent $-w h y$ they are made. In particular, our empirical analysis suggests that users seek to sever their entanglement with their avatar when the identity performance becomes too real. While this insight has been developed using an extreme case [34], future research is needed to assess whether this key finding will hold in technological settings other than Second Life, e.g. social media such as Facebook, Instagram and Twitter, and other virtual worlds, e.g. Minecraft, World of Warcraft.

\section{References}

1. Boland, R.J., Jr: The Engine of Inquiry, or "Why Say Anything at All?”. In: Polesie T. and Johansson, I. (eds) Responsibility and Accounting: The Organizational Regulation of Boundary Conditions. Studentlitteratur: Lund, Sweden (1992)

2. Barad, K.: Meeting the Universe Halfway: Quantum Physics and the Entanglement of Matter and Meaning. Duke University Press, Durham \& London (2007)

3. Madge, C. and H. O'Connor: Mothers in the Making? Exploring Liminality in Cyber/Space. Transactions of the Institute of British Geographers. 30(1), 83-97 (2005)

4. Borer, M.I.: The Cyborgian Self: Toward a Critical Social Theory of Cyberspace. Reconstruction: Studies in Contemporary Culture. 2(3), http://reconstruction.eserver.org/023/borer.htm (2002)

5. Nyberg, D.: Computers, Customer Service Operatives and Cyborgs: Intra-actions in Call Centres. Organization Studies. 30(11), 1181-1199 (2009)

6. Giddens, A.: Modernity and Self-Identity: Self and Society in the Late Modern Age. Polity Press, Cambridge (1991)

7. Van Doorn, N.: Digital Spaces, Material Traces: How Matter Comes to Matter in Online Performances of Gender, Sexuality and Embodiment. Media, Culture \& Society. 33(4), 531-547 (2011)

8. Shields, R.: The Virtual. Routledge, London (2003)

9. Boland, R.J. and R. Tenkasi: Metaphor and the Embodied Mind: An Engine of Organizational Inquiry. Sprouts: Working Papers on Information Environments, Systems and Organizations. 1(1), 21-39 (2001)

10. Turkle, S.: Life on the Screen: Identity in the Life of the Internet. Simon \& Shuster, New York (1995) 
11. Whitley, E.A.: In Cyberspace All They See Is Your Words: A Review of the Relationship Between Body, Behavior and Identity Drawn from the Sociology of Knowledge. Information Technology \& People. 10(2), 147-163 (1997)

12. Robinson, L.: The Cyberself: The Self-ing Project Goes Online, Symbolic Interaction in the Digital Age. New Media \& Society. 9(1), 93-110 (2007)

13. Kendall, L.: Hanging Out at the Virtual Pub: Masculinities and Relationships Online. University of California Press, Berkley, CA (2002)

14. Shiano, D.J.: Lessons from LambdaMOO: A Social, Text-Based Virtual Environment. Presence. 8(2), 127-139 (1999)

15. Jin, S.-A.A.: Avatars Mirroring the Actual Self Versus Proejcting the Ideal Self: The Effects of Self-Priming on Interactivity and Immersion in an Exergame, Wii Fit. CyberPsychology \& Behavior. 12(6), 761-765 (2009)

16. Bessiere, K., A.F. Seay, and S. Kiesler: The Ideal Elf: Identity Exploration in World of Warcraft. CyberPsychology \& Behavior. 10(4), 530-535 (2007)

17. Hickey-Moody, A. and D. Wood: Virtually Sustainable: Deleuze and Desiring Differenciation in Second Life. Continuum: Journal of Media and Cultural Studies. 22(6) 805-816 (2008)

18. Vaast, E.: Playing with Masks: Fragmentation and Continuity in the Presentation of Self in an Occupational Online Forum. Information Technology \& People. 20(4), 334-351 (2007)

19. Butler, J.: Bodies that Matter. Routledge, London (1993)

20. Schultze, U.: Performing Embodied Identity in Virtual Worlds. European Journal of Information Systems. 23(1), 84-95 (2014)

21. Lee, K.M.: Presence, Explicated. Communication Theory. 14(1), 27-50 (2004)

22. Kreps, D.: My Social Networking Profile: Copy, Resemblance or Simulacrum? A Poststructuralist Interpretation of Social Information Systems. European Journal of Information Systems. 19(1), 104-115 (2010)

23. MacKenzie, D., F. Muniesa, and L. Siu (eds): Do Economicsts Make Markets? On the Performativity of Economics. Princeton University Press: Princeton, NJ (2007)

24. Strathern, M.: Abstraction and Decontextualization: An Anthropological Comment. In: Woolgar, S. (ed.) Virtual Society? Technology, Cyberbole, Reality, pp. 302-313. Oxford University Press: Oxford (2002)

25. Brandt, L.W. and W. Metzger: "Reality": What Does it Mean?. Psychological Reports. 29, 127-135 (1969)

26. Taylor, T.L.: Play Between Worlds: Exploring Online Game Culture. MIT Press, Cambridge, MA (2006)

27. Barley, S. and G. Kunda: Design and Devotion: Surges of Rational and Normative Ideologies of Control in Organizational Discourse. Administrative Science Quarterly. 37, 363-399 (1992)

28. Lakoff, G. and M. Johnson: Metaphors We Live By. University of Chicago Press, Chicago (1980)

29. Quinn, N.: The Cultural Basis of Metaphor. In: Fernandez, J.W. (ed.) Beyond Metaphor: The Theory of Tropes in Anthropology, pp. 56-93. Stanford University Press: Stanford, CA (1994)

30. Goffman, E.: The Presentation of Self in Everyday Life. Doubleday, Garden City, NY (1959)

31. Giddens, A.: The Transformation of Intimacy: Sexuality, Love and Eroticism in Modern Society. Polity Press, Cambridge (1992) 
32. Turkle, S.: Alone Together: Why We Expect More from Technology and Less from Each Other. Basic Books, New York (2011)

33. Austin, J.: How to Do Things with Words. Harvard University Press, Cambridge, MA (1962)

34. Eisenhardt, K.M.: Building Theories from Case Study Research. Academy of Management Review. 14(4), 532-550 (1989)

35. Latham, A.: Research, Performance and Doing Human Geography: Some Reflections on the Diary-Photograph, Diary-Interview Method. Environment and Planning A. 35(11), 1993-2017 (2003) 